\title{
GAMBARAN ATTITUDE TOWARDS BEHAVIOR PENYALAHGUNAAN NARKOBA PADA REMAJA SMA KOTA JAMBI
}

\section{AN OVERVIEW OF ATTITUDE TOWARDS BEHAVIOR OF DRUG ABUSE IN SENIOR HIGH SCHOOL STUDENTS IN JAMBI CITY}

\author{
Ratu Aulia Qonita ${ }^{1}$ \\ Siti Raudhoh ${ }^{2}$ \\ Dessy Pramudiani ${ }^{3}$
}

\begin{abstract}
${ }^{1}$ Departement of Psychology, Jambi University/ratuauliaqonita4@gmail.com
${ }^{2}$ Departement of Psychology, Jambi University/siti_raudhoh@unja.ac.id

${ }^{3}$ Departement of Psychology, Jambi University/ dessy_psychology@ gmail.com
\end{abstract}

\begin{abstract}
Introduction Drug abuse in adolescence is in high rate. Many factors that encourage adolescents to commit drug abuse behavior, one of which is attitude towards behavior, which is an individual's good or bad assessment of drug abuse behavior.

Method This research was a quantitative study with a descriptive and cross-sectional method. This research was conducted at State and Private Senior High Schools in Jambi City with 380 sample who were determined through the Purposive Sampling Technique. Data collection is done online using Aida form.The analysis used descriptive statistics with the JASP 0.9.0.0 application.
\end{abstract}

Results This study shows the results in the attitude towards behavior category are very negative at $8 \%$, negative $28 \%$, neutral by $30 \%$, positive $26 \%$, and very positive at $8 \%$.

Conclusion And Recommendation Jambi City High School adolescents have a neutral attitude towards behavior of drug abuse. By conducting this research, it is hoped that it can become a solution to prevent drug abuse in high school adolescents in Jambi City.

Keywords: attitude towards behavior, drug abuse

\begin{abstract}
ABSTRAK
Pendahuluan Penyalahgunaan narkoba di usia remaja berada pada angka yang tinggi. Banyak faktor yang dapat mendorong remaja memiliki intensi melakukan perilaku penyalahgunaan narkoba, diantaranya attitude towards behavior, subjective norm, perceived behavioral control. Setiap faktor tersebut memiliki peranan masing-masing dalam tinggi atau rendahnya intensi perilaku penyalahgunaan narkoba pada remaja khususnya siswa SMA Kota Jambi.

Metode Penelitian ini merupakan penelitian kuantitatif dengan metode korelasional dan bersifat cross-sectional. Penelitian ini dilakukan pada SMA Negeri dan SMA Swasta di Kota Jambi dengan jumlah sampel 380 orang yang ditentukan melalui Teknik Purposive Sampling. Analisis yang dilakukan yaitu regresi berganda, uji korelasi, T- Test (Independen Sample) dan F-Test (Anova One Way) menggunakan aplikasi JASP 0.9.0.0.
\end{abstract}

Hasil Penelitian ini menunjukkan hasil attitude towards behavior, subjective norm, dan perceived behavioral control memberikan kontribusi efektif sebesar $37 \%$ terhadap variabel 
intensi penyalahgunaan narkoba, dengan kontribusi tertinggi diberikan oleh perceived behavioral control.

Kesimpulan Dan Saran Attitude towards behavior, subjective norm, dan perceived behavioral control memiliki kontribusi dan hubungan dengan Intensi perilaku penyalahgunaan narkoba. Dengan dilakukannya penelitian ini diharapkan dapat menjadi solusi pencegahan penyalahgunaan narkoba pada remaja SMA Kota Jambi.

\section{Pendahuluan}

Permasalahan penyalahgunaan dan peredaran gelap narkoba merupakan permasalahan dunia yang tidak kunjung selesai. Permasalahan narkoba membuat setiap negara waspada terhadap penyalahgunaan dan peredaran gelap narkoba. Narkoba dapat merugikan dan membahayakan masyarakat dalam kehidupan berbangsa dan bernegara, selain itu juga dapat menjadi masalah bagi ketahanan nasional Negara Indonesia.

Di Indonesia penyalahgunaan narkoba terjadi pada berbagai tatanan masyarakat, hampir tidak ada daerah atau wilayah Provinsi yang bebas dari narkoba. Berdasarkan hasil survei nasional terkait penyalahgunaan narkoba di 34 Provinsi tahun 2017 yang dilaksanakan oleh Puslitdatin BNN RI bekerjasama dengan Pusat Penelitian Kesehatan Universitas Indonesia (UI) disebutkan bahwa angka prevalensi penyalahgunaan narkoba di Indonesia pada tahun 2017 yaitu 1,7\% atau estimasi jumlah penyalahguna narkoba pada kelompok 10-59 tahun dalam satu tahun sebanyak 3,3 juta orang (Deputi Bidang Rehabilitasi BNN RI, 2018). Tingginya angka prevalensi tersebut merupakan angka yang mengkhawatirkan.

Menurut survei tersebut diketahui bahwa proporsi penyalahgunaan terbesar terjadi pada kelompok pekerja dengan angka 59\%, kemudian disusul oleh kelompok remaja sebanyak $24 \%$, dan populasi umum sebanyak $19 \%$. Sasaran utama peredaran gelap narkoba yaitu kelompok yang rentan terpengaruh dan terjerumus pada usia remaja.

Penyalahgunaan narkoba biasanya terjadi pada masa remaja usia pelajar SMP atau SMA, ini disebabkan karena tawaran, bujukan, atau tekanan dari orang sekitar.
Kemudian muncul rasa ingin tahu, cobacoba, serta bersedia menerima ajakan, lalu tidak sedikit mereka mengalami kecanduan dan ketergantungan. (Martono \& Joewana, 2008).

Ditresnarkoba Polda Jambi dan Satresnarkoba Polresta Jambi mencatat setiap tahunnya terdapat remaja usia SMA yang menjadi tersangka penyalahgunaan narkoba di Kota Jambi. Berikut data jumlah tindak pidana penyalahgunaan narkoba di Kota Jambi untuk usia 15-19 tahun dari tahun 2017-2019.

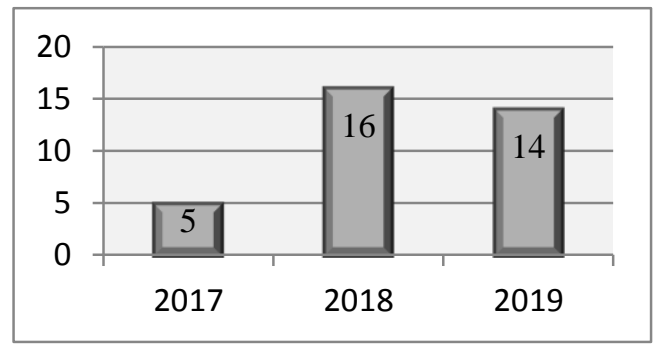

Gambar 1.1. Data JTP kasus narkoba di

Kota Jambi untuk usia 15-19 tahun.

Berdasarkan data tersebut, dapat dilihat bahwa remaja menjadi salah satu target pasar narkoba. Remaja menjadi incaran para pengedar narkoba karena masa remaja merupakan masa emosi labil, storm and stress, masa pencarian identitas, dan masa transisi dari anak-anak ke dewasa, rentan mengalami pengaruh negatif dari teman sebaya.

Ariani (2012) menyebutkan salah satu ciri tahap perkembangan psikososial remaja adalah berorentasi pada pengalaman baru dan keingintahuan yang tinggi, dampak yang dapat timbul apabila tahap perkembangan tersebut tidak terlaksana dengan baik maka akan mengarah ke hal negatif seperti mulai bereksperimen dengan rokok, seks bebas, dan narkoba. 
Penelitian Ayu dan Saputra (2015) menunjukkan bahwa salah satu perilaku berisiko remaja khususnya siswa SMA di kota jambi adalah penyalahgunaan narkoba. Dari hasil penelitian diketahui terdapat kecenderungan pengguna narkoba pada beberapa siswa, minuman keras merupakan jenis minuman yang digunakan ketika berkumpul bersama teman, narkoba mudah didapatkan dengan membeli sendiri menggunakan uang saku, diberi teman secara sokongan, narkoba juga didaptkan oleh mereka dengan cara mencuri.

Penyalahgunaan narkoba terdiri dari berbagai jenis yang tergolong narkotika, psikotropika, bahan adiktif lainnya (Hawari, 2001). Berdasarkan hasil Survei BNN, Narkoba yang biasa disalahgunakan adalah amphetamin (sabu), ganja, dan alkohol (BNN, 2018).

Dampak bagi penyalahgunaan narkoba pada remaja SMA berkaitan dengan proses belajar, dimana remaja SMA akan merasakan pengaruh seperti malas belajar, mudah lupa, sulit konsentrasi, dan lain-lain. Penyalahgunaan narkotika dapat merusak sel-sel pada sistem otak remaja, sehingga mengakibatkan otak tidak berfungsi dengan normal (Pulungan, 2015).

Faktor risiko penyalahgunaan narkoba pada remaja atau pelajar dipengaruhi oleh berbagai macam sebab, beberapa diantaranya seperti agar dapat diterima oleh lingkungan, mengurangi stres, mengurangi kecemasan, agar bebas dari rasa murung, mengurangi keletihan, kejenuhan atau kebosanan, mengatasi masalah pribadi, dan lain-lain (Tambunan, 2008).

Penelitian Sarake (2013) di Makassar menunjukkan bahwa siswa yang mengkonsumsi narkoba cenderung memiliki keluarga yang tidak harmonis. Tingginya konformitas teman sebaya dan rendahnya religiusitas menyebabkan kecenderungan remaja untuk melakukan penyalahguna narkoba.

Agustin (2014) dalam penelitiannya juga menunjukkan bahwa terdapat faktor yang berhubungan dengan penyalahgunaan narkoba antara lain tingkat religiusitas yang rendah, peranan keluarga yang kurang baik terhadap pencegahan penyalahgunaan narkoba, teman yang berperan dalam memperkenalkan narkoba. Pulungan (2015) mengungkapkan bahwa mayoritas pelajar yang menyalahgunakan narkoba diakibatkan dari pergaulan luar sekolah yang tidak terkontrol dan berisiko.

Berdasarkan wawancara terhadap klien remaja bernama AN (15 tahun) yang merupakan pelajar SMA untuk mengetahui motif penyalahgunaan narkoba. Wawancara dilakukan di Klinik Pratama, Bidang Rehabilitasi BNNP Jambi pada tanggal 10 September 2019 pukul 10.15 WIB.

"Awalnya yo cuman untuk pelengkap pas ngumbul bae, biak lepas kalau ngomong jadi seru kalau nongkrong. Nah, kalau shabu tu awalnyo karna saya pusing dengan keluarga saya. Orang tua saya pisah, saya tinggal dengan keluarga besar, ada ibu, kakek, nenek, oom dan tente. Saya dirumah tidak diperdulikan dan dimarahi terus, setiap yang saya lakukan selalu salah, nonton tv saja dimarahi. Tidak ada gunanya saya dirumah, ibu saya, kakek saya, oom saya cuek dengan saya. Saya disekolah juga bodoh. Hanya teman sesama pemakai yang bisa mengerti saya dan membuat saya senang, mending saya sama teman saya. Kalau lagi makai tu senang, lupa kalau habis dimarahin"

Berdasarkan kutipan wawancara di atas, diketahui bahwa remaja tersebut berpersepsi bahwa dia merasakan sensasi rasa senang ketika menggunakan narkoba. remaja tersebut memiliki keyakinan bahwa narkoba dapat membuatnya senang sehingga sikapnya terhadap narkoba menjadi positif.

Masa remaja yang berada pada fase topan dan badai mengakibatkan remaja akan sulit mengendalikan diri ketika menghadapi masalah atau situasi tidak menyenangkan. Hal tersebut sejalan dengan hasil wawancara pada Konselor adiksi di yayasan Natura Rehabilitation center Jambi. Wawancara dilakukan pada Konselor yang bernama ST (28 th) pada tanggal 17 Desember 2019 pukul 14.00 WIB.

"Otak remaja itu lebih mudah untuk hancur. Jadi misal kita bicara cara bagaimana mulainya kecanduan narkoba banyak lah,mulai dari lingkungan juga 
orang tua khususnya. Saya pernah ketemu klien yang direhab di natura, harapan dia hanya satu, bisa makan satu meja dengan keluarga. Jadi sehabis rehabilitasi itu bukan hanya dirinya yang diperbaiki tapi juga keluarganya. Makanya keluarga juga ikut dilibatkan disini, misal melaksanakan support group, jadi yaitu misalnya keluarga otoriter sementara klien ini tidak bisa di otoriterkan, kan disitu keluarga harus diubah, semisal ayah tidak harus otoriter, yang bisa menjadi sahabat."

Remaja merupakan individu yang terikat dengan kelompok, remaja butuh orang terdekat yang mampu membimbingnya ke arah yang baik, sehingga tidak terjerumus pada hal-hal negatif. Jika sosok orang terdekat remaja tidak memberi pengaruh positif pada remaja, remaja akan mudah terjerumus pada perilaku berisiko.

Faktor dari dalam diri juga dapat mempengaruhi remaja dalam memilih untuk menyalahgunakan narkoba, seperti rasa ingin tahu. Naluri keingintahuan atau penasaran pada remaja setelah mendengar rasa nikmat yang diporeleh temannya saat menggunakan narkoba dapat mendorong remaja pada penyalahgunaan narkoba. Pengalaman remaja ketika melihat temannya menikmati narkoba dapat menjadi evaluasi remaja untuk bersikap terhadap perilaku penyalahgunaan narkoba. Rasa penasaran akan narkoba disebutkan konselor adiksi RSJD Jambi dalam wawancara pada tanggal 17 Desember 2019 pukul 10.00 WIB di Instalasi Narkoba LAMBDA, Rumah Sakit Jiwa Daerah Jambi.

"Banyak sih alasannya. Ada yang mau coba-coba awalnya, terus ada juga yang dikarenakan faktor lingkungan, rasa penasaran, untuk faktor alasan menggunakan karena ada masalah itu jarang sekali. Ada sih yang seperti itu, tapi mereka awalnya ingin mencari teman untuk curhat tapi mereka salah memilih teman dan dijerumuskan untuk menggunakan narkoba."

Pada umumnya pelajar memiliki rasa ingin tahu dan mencoba hal-hal baru, sehingga remaja rentan terhadap perilaku negatif dan menyimpang berupa penyalahgunaan narkoba. Motif lain terjadinya penyalahguaan narkoba karena adanya kesempatan, sarana dan prasarana, ketidakstabilan emosi hingga lemahnya kontrol diri. (Suarjana \& Putra, 2018).

Sebelum remaja melakukan penyalahgunaan narkoba, terdapat proses dari pengalaman yang ia alami, misalnya melihat teman atau dari lingkungan sekitar. Proses tersebut dapat mempengaruhi sikap dan persepsinya terhadap narkoba, kemudian pengaruh pandangan. Sikap terhadap perilaku atau attitude towards behavior merupakan penilaian baik atau buruk dari individu atas perilaku penyalahgunaan narkoba, jika individu menilai bahwa suatu perbuatan penyalahgunaan narkoba dipandang perbuatan yang tidak baik, maka sikap orang tersebut akan menentukan perilakunya. (Ajzen, 2012).

Dengan menimbang besarnya dampak kerugian penyalahgunaan narkoba, semakin banyaknya pelajar terlibat penyalahgunaan narkoba, peneliti tertarik untuk mengetahui bagaimana gambaran attitude towards behavior penyalahgunaan narkoba.

Penelitian terkait sikap terhadap perilaku penyalahgunaan narkoba pada remaja belum banyak dilakukan, terutama di kota Jambi. Oleh karena itu, untuk mencegah semakin tingginya angka penyalahgunaan narkoba pada remaja SMA di Kota Jambi, perlu adanya penelitian terkait gambaran attitude towards behavior penyalahgunaan narkoba pada remaja SMA Kota Jambi.

\section{Metode}

Penelitian ini bertujuan untuk mengetahui gambaran attitude towards behavior pada remaja SMA Kota Jambi. Penelitian ini merupakan penelitian kuantitatif yang menggunakan metode Deskriptif. Populasi dalam penelitian ini merupakan remaja yang sedang menjalani pendidikan Sekolah Menengah Atas (SMA) di Kota Jambi. Sedangkan Sampel pada penelitian ini berjumlah 380 siswa SMA yang ditentukan menggunakan teknik purposive sampling. 
Instrumen yang digunakan dalam pengumpulan data adalah kontruksi alat ukur skala likert attitude towards behavior, subjective norm. Pengumpulan data dilakukan secara daring menggunakan Aida form yang disebarkan secara daring di berbagai media sosial, seperti facebook, instagram, dan whatsapp.

Analisis data berupa analisis statistik desktiptif menggunakan aplikasi JASP 0.9.0.0.

\section{Hasil dan Pembahasan}

Deskripsi data penelitian Attitude Towards Behavior dapat dilihat pada tabel berikut:

Tabel 1. Statistik Deskriptif

\begin{tabular}{cccccc} 
Variabel & N & Min. & Max. & M & SD \\
\hline $\begin{array}{c}\text { Attitude } \\
\text { Towards }\end{array}$ & 380 & 24 & 77 & 49,27 & 14,35 \\
Behavior & & & & & \\
\hline
\end{tabular}

Berdasarkan tabel di atas dapat dilihat bahwa secara hipotetik skala attitude towards behavior memiliki skor tertinggi sebesar 77, skor terendah sebesar 24, skor rata-rata sebesar 49,3 dan standar deviasi sebesar 14,35. Data penelitian ini selanjutnya untuk mengkategorikan subjek penelitian agar skor yang diperoleh subjek dapat diinterpretasi.

Tabel 2. Deskripsi Data Penelitian

\begin{tabular}{ccccc}
\hline Variabel & $\begin{array}{c}\text { Rentang } \\
\text { Skor }\end{array}$ & Klasifikasi & F & P \\
\hline & $\mathrm{X} \leq 28$ & Sangat Negatif & 32 & $8 \%$ \\
Attitude & $28<\mathrm{X} \leq 42$ & Negatif & 107 & $28 \%$ \\
Towards & $42<\mathrm{X} \leq 56$ & Netral & 113 & $30 \%$ \\
Behavior & $56<\mathrm{X} \leq 70$ & Positif & 97 & $26 \%$ \\
& $\mathrm{X}>70$ & Sangat Positif & 31 & $8 \%$ \\
\hline & & Total & $\mathbf{3 8 0}$ & $\mathbf{1 0 0 \%}$ \\
\hline
\end{tabular}

Berdasarkan tabel di atas, pada kategori attitude towards behavior dengan klasifikasi sangat negatif terdapat 32 subjek dengan persentase sebanyak $8 \%$, pada kategori attitude towards behavior negatif terdapat 107 subjek dengan persentase sebanyak $28 \%$, pada kategori attitude towards behavior netral terdapat 113 subjek dengan persentase sebanyak $30 \%$, pada kategori attitude towards behavior positif terdapat 97 subjek dengan persentase sebanyak $26 \%$, dan pada kategori attitude towards behavior sangat positif terdapat 31 subjek dengan persentase sebanyak $8 \%$.

Data yang diperoleh berdasarkan respon subjek menunjukkan bahwa kecenderungan skor subjek berada pada kategori attitude towards behavior sedang dan attitude towards behavior rendah.

Gambaran attitude towards behavior subjek, yaitu dominan pada sikap negatif terhadap perilaku penyalahgunaan narkoba dengan persentase sebanyak $28 \%$ dan sikap netral dengan persentase sebanyak $30 \%$. Hal ini berarti subjek memiliki keyakinan terhadap kerugian dari penyalahgunaan narkoba dan mengevaluasi keyakinan tersebut hingga membentuk sikap terhadap perilaku penyalahgunaan narkoba. Berdasarkan hasil penelitian yang dilakukan Hayati (2019) pada remaja Kota Jambi, diketahui bahwa sebanyak 53,9\% responden memiliki sikap postif terhadap bahaya narkoba.

Menurut Sarwono (2009), sikap merupakan proses evaluasi yang sifatnya internal atau subjektif, yang berlangsung dalam diri seseorang dan tidak dapat diamati secara langsung. Sikap dapat diketahui melalui pengetahuan, keyakinan, perasaan dan kecenderungan tingkah laku seseorang terhadap objek sikap. attitude toward behavior atau sikap menurut Ajzen (2005) adalah evaluasi secara positif atau negatif terhadap benda, orang, institusi, kejadian, perilaku atau minat tertentu. Seseorang yang yakin jika suatu perilaku akan mengarahkan kepada hasil yang positif, maka orang tersebut akan memiliki sikap favorable dan juga sebaliknya jika seseorang yakin bahwa suatu perilaku yang ditampilkan akan mengarahkan kepada hasil yang negatif, maka orang tersebut akan bersikap unfavorable.

Attitude towards behavioral ditentukan dari keyakinan individu terhadap konsekuensi perilaku. Individu akan bersikap sesuai dengan keyakinannya megenai konsekuensi yang akan individu peroleh.

Keyakinan akan menghubungkan setiap perilaku dengan hasil tertentu, sehingga akan terbentuk sikap terhadap perilaku tersebut. Jika individu percaya 
akan memperoleh hasil yang menguntungkan dari suatu perilaku maka ia akan memiliki keyakinan yang positif, sementara jika individu percaya memperoleh hasil yang tidak menguntungkan dari suatu perilaku maka dia akan memiliki keyakinan yang negatif. Keyakinan positif akan menghasilkan sikap yang positif dan keyakinan negatif akan menghasilkan sikap negatif.

Sikap ditentukan oleh evaluasi individu terhadap hasil yang berkaitan dengan perilaku. Evaluasi terhadap hasil yang tampak dari suatu perilaku akan berkontibusi dalam sikap individu. Jika pada keyakinan di bahas menganai rasa percaya individu pada hasil yang akan di peroleh, namun evaluasi mengkaji mengenai hasil yang terlihat dari suatu perilaku. Evaluasi dapat menambah atau menurunkan tingkat keyakinan individu. Keyakinan dan evaluasi memiliki hubungan yang erat dalam penentuan sikap individu terhadap perilaku.

Seseorang yang yakin bahwa suatu perilaku dapat menghasilkan outcome yang positif, maka individu tersebut akan memiliki sikap yang positif, dan begitu juga sebaliknya jika seseorang yakin bahwa perilaku yang akan ditampilkan memiliki outcome yang negatif, maka individu tersebut akan memiliki sikap yang negatif. Sikap dikatakan sebagai suatu respon evaluatif. Respon hanya akan timbul apabila individu dihadapkan pada suatu stimulus yang menghendaki adanya reaksi individual. Respon evaluatif berarti bahwa bentuk reaksi yang dinyatakan sebagai sikap itu timbulnya didasari oleh proses evaluasi dalam diri individu yang memberi kesimpulan terhadap stimulus dalam bentuk nilai dalam bentuk baik-buruk, positifnegatif, serta menyenangkan dan tidak menyenangkan yang kemudian terbentuk sebagai potensi reaksi terhadap objek sikap (Azwar, 2011).

Subjek yang memiliki sikap negatif terhadap perilaku penyalahgunaan narkoba kemungkinan memiliki intensi yang rendah untuk melakukan perilaku tersebut, namun tidak menutup kemungkinan subjek yang memiliki intensi yang rendah memiliki sikap positif terhadap perilaku penyalahgunaan narkoba.

Tingginya responden yang berada pada sikap netral. Sikap netral ini dapat bergeser tergantung pengalaman dan pengetahuan yang diperoleh individu. Oleh karena itu perlu tindakan pencegahan yang fokus pada pembentukan sikap negatif terhadap penyalahgunaan narkoba pada remaja.

\section{Kesimpulan dan Saran}

Berdasarkan hasil penelitian yang telah dilakukan pada remaja siswa SMA di Kota Jambi, maka dapat disimpulkan bahwa attitude towards behavior remaja siswa SMA di Kota Jambi berada pada kategori netral dengan persentase sebesar $30 \%$.

Berdasarkan hasil penelitian ini, peneliti juga memberi saran yang ditujukan kepada beberapa pihak diantaranya kepada Instansi Pencegahan Penyalahgunaan Narkoba, pencegahan penyalahgunaan narkoba dapat dilakukan dengan kegiatan yang membentuk sikap negatif yang akan memperkecil kemungkinan munculnya perilaku penyalahgunaan narkoba pada remaja. Sedangkan untuk penelitian selanjutnya dapat menggunakan dan mengkaji varibel lain lebih lanjut.

\section{Daftar Pustaka}

Agustin, H., \& Rahmadona, E. (2014). Faktor yang Berhubungan dengan Penyalahgunaan Narkoba di Rsj Prof. $\mathrm{Hb}$. Sa'anin. Andalas Journal of Public Health, 8(2).

Ajzen, I. (2002). Perceived Behavioral Control, Self-Efficacy, Locus of Control, and the Theory of Planned Behavior. Journal of Applied Social Psychology. 32(4).

Ajzen, I. (2012). Attitudes and Persuasion. In K. Deaux \& M. Snyder (Eds.), The Oxford Handbook of Personality and Social Psychology. New York: Oxford University Press. DOI: 10.1093/oxfordhb/9780195398 991.013.0015. 
Ariani, R. (2012). Kesehatan Remaja: Problem dan Solusinya. Jakarta: Salemba Medika.

Ayu, N. N., \& Saputra, N. E. (2015). The Influence Cognitive Behavioral Therapy To Resilience in Adolescents at Risk. Jambi Medical Journal "Jurnal Kedokteran dan Kesehatan". 3(1). https: //doi.org/ 10.22437/jmj.v3i1.2716.

Azwar, S. (2013). Sikap Manusia: Teori dan Pengukurannya. Yogyakarta: Pustaka Pelajar.

BNN (Badan Narkotika Nasional). (2018). Jurnal Data Puslidatin Tahun 2018 Indonesia: Narkoba Dalam Angka Tahun 2017. Jakarta : BNN RI.

Hawari, D. (2001). Penyalahgunaan \& Ketergantungan NAZA (Narkotika, Alkohol, \& Zat Adiktif). Jakarta: Balai Penerbit FKUI.

Hayati, F. (2019). Penyuluhan Bahaya Penyalahgunaan NAPZA terhadap Sikap Reaja di SMPN 13 Kota Jambi. Jurnal Kesehatan Al-Irsyad. 12(1).

Martono, L. H. \& Joewana, S. (2008). Pencegahan dan Penanggulangan Penyalahgunaan Narkoba Berbasi Sekolah: Panduan Guru, Konselor dan Administrator. Jakarta: Balai Pustaka.
Pulungan, M. S. (2016). Kajian Dampak Narkoba di Kalangan Pelajar SLTPSLTA di Kabupaten Kutai Kartanegara Provinsi Kaltim. Jurnal Pendidikan dan Pembelajaran (JPP), 22(1), 082-093.

Sarake, M. dkk. (2013). Faktor Yang Berhubungan Dengan Penyalahgunaan Narkotika dan Bahan Adiktif (Narkoba) Pada Remaja di SMA Kartika Wirabuana XX-1 Makassar. Jurnal MKMI. 9 (3).

Sarwono, S. W. (2010). Psikologi Remaja. Jakarta: Rajawali Pers.

Suarjana, A. A. \& Putra, I. M. (2018). Pengaruh Sikap, Norma Subjektif dan Persepsi Kontrol perilaku yang dipersepsikan Terhadap Intensi Perilaku Penyalahgunaan Narkoba pada Mahasiswa Politeknik Negeri Bali. Jurnal Organisasi dan Manajemen. 14(2).

Tambunan, R. Dkk. (2008). Beberapa Faktor yang Berhubungan dengan Perilaku Penggunaan Napza pada Remaja di Balai Pemulihan Sosial Bandung. Jurnal Keperawatan Indonesia, 12(2). 